only Malay, more or less modified according to the national idiosyncrasies of the speaker. Moreover, many of the Malayan loan-words are pronounced, not as the Makays of the peninsula pronounce them today, but as it would seem they were pronounced when Malay was first written in Arabic characters; thus the $k$ still pronounced in Borneo also occurs in the aboriginal dialects. Besides unidentified elements, many constituents of both Semang and Sakai dialects agree with the Mon-Khmer languages, but whether this similarity be due to all these languages being essentially members of one family or to the direct contact of Semang and Sakai with Mon-Khmer peoples is uncertain, though, of course the two views do not necessarily exclude each other. There is a most interesting chapter on tabu language and other special forms of speech, and the work concludes with a comparative vocabulary of the aboriginal dialects which is so arranged as to be particularly easy to use.

C. G. S.

\section{ELECTRIC POWER IN LONDON.}

$\mathrm{U}$ NTIL a couple of years ago the problem of electricity supply in London was mainly one of interest to engineers and investors. Its introduction into the realm of municipal politics, however, has given it a wider interest, and one that tends to obscure the purely scientific aspect of the problem. Alike in connection with water, with gas, and with electricity, London has suffered from the fact of its slow growth and of its being composed of a number of separate towns and districts; its very magnitude, which to-day would enable it to be supplied with electricity more cheaply than any other great city, has been the chief hindrance to its getting such a supply. The enormous number of authorities authorised to supply electricity in Greater London, which at the present time exceeds seventy, has resulted in the establishment of nearly sixty generating stations, many of which are of comparatively small size and inefficient design. The municipal authorities have also been confined to their own boundaries and compelled to choose uneconomical sites, and any attempts at combination between the various authorities which might have enabled them to secure some of the advantages of production on a larger scale have been prevented by the restrictive legislation under which they operate, legislation which was originally passed before the future developments of electricity production were appreciated, while the still more remarkable developments in the uses of electric power wert entirely unforeseen. An attempt at concentration was long ago made by the London Electric Supply Corporation, which established its great station at Deptford. That it was not successful was not due to any unsoundness of the principle upon which it was based, but to the fact that it was before its time. Fifteen years afterwards, in 1905, a fresh proposal embodying the first step in the policy of concentration was brought forward by a private company; several of the existing companies at the same time brought forward proposals, not for complete concentration, but for dividing London into three areas, in each of which a supply would be ultimately centralised.

The former scheme, due to its novelty and comprehensive nature, aroused considerable controversy. It was framed on the lines of the various Power Acts which Parliament has passed during the past five years. That is to say, it did not deal with retail supply of lighting, but only authorised wholesale supply of electricity and the retail supply of power in cases where the Board of Trade thought such supply should be given. Its main object was the

$$
\text { No. I 948, VOL. } 75]
$$

establishment of two stations, in which generation would take place on a scale much larger than that of any station in London to-day, and from which electricity would be supplied wholesale to the various distributing authorities by whom it would be retailed to the consumer. The limited right to supply the power consumer direct, in certain cases, was inserted by Parliament in order to ensure that the distributor should not absorb all the advantages of wholesale production.

This scheme naturally aroused much opposition from the existing authorities, both municipal and company. To a large extent, however, this disappeared as the real nature of the Bill became known; in fact, practically all the leading companies, and many of the most business-like local authorities, appreciating the advantages of purchasing a bulk supply in place of having constantly to expend further capital on extending their own smaller generating stations, entered into agreements with the promoters. The manufacturing interests of London also supported the scheme very warmly, and a deputation of leading manufacturers waited upon the Board of Trade, and showed that if the East End could obtain power at the prices fixed by the Bill it would mean an annual saving of nearly $3,000,000 l$ as compared with the present methods of power production. A petition, signed by employers of 100,000 hands, was also presented to Parliament in favour of the scheme.

It was, however, strongly opposed by the London County Council, which, in spite of numerous modifications and safeguards, such as the sliding scale of price and dividend, and the purchase clause, which were inserted in the Bill by Parliament, contended that it was not in the public interest that such a scheme should become law. It, however, passed Committees of both Houses, but so late in the session that it failed to become law.

In the next session of Parliament, rgo6, the County Council itself introduced a scheme. The 1905 company's Bill was also re-introduced, and a new scheme was brought forward by the existing companies for linking up their systems and removing the restrictions upon mutual supply to which reference has already been made. The County Council's scheme alone received a second reading, and was sent to a special Hybrid Committee with instructions to consider the whole question.

The County Council's scheme dealt with wholesale supply only; it was strongly criticised by the Council's own Finance Committee, and unanimously rejected by the House of Commons Committee which had been instructed specially to consider it. The Report of that Committee recommended, however, that the Council should be made the controlling authority for electricity supply, but as regards the carrying out of the undertaking suggested that the Council should consider cooperation with private enterprise.

This year the Council has brought forward a more comprehensive scheme, involving nothing less than a monopoly of electricity supply for all nurposes over 450 square miles, 330 of which are outside the county. Fourteen of the borough council undertakings are to be compulsorily acquired within five years, the thirteen company undertakings as their concessions lapse. Undertakings outside the county of London are to be acquired by agreement, but until it has secured this monopoly, and to assist in securing it, the Council takes powers to compete (for power supply only) with all these undertakings.

From a scientific point of view the principle of concentration would appear to be correct, but whether electricity supply has reached a state of development when such a big step forward as that proposed by 
the Council would be wise is somewhat doubtful. There is no engineering impossibility in wiping out all the existing generating stations with their various systems of supply and in producing the whole of the electricity required for London in a station erected at Barking or Erith, as the Council proposes. But from the financial point of view the magnitude of the scheme appears to be its chief difficulty. Seventeen millions have already been sunk in electricity supply in London, and, according to a careful estimate in a leading financial journal, this sum would have to be nearly doubled before the Council could secure the monopoly at which it aims. Before embarking upon such a scheme, from which when once started there is no turning back, the ratepayers need to be very sure of the future developments of electricity. Three times in the past twenty years have the prime movers used for electrical production been entirely changed. The slow-speed horizontal engines which had been developed during the nineteenth century were first used, and gave place during the 'eighties to high-speed engines of the single-acting or forced-lubricating type for electrical supply. These are now being replaced by steam turbines. Many inventors are, however, at work upon the improvement of large gas engines and other internal-combustion machines, and the attempts which have been made to construct a satisfactory internal-combustion turbine may any day bear fruit.

Now it is obvious that if electricity production in London should become municipalised, so far as London is concerned the rate of development and the adoption of improved methods will be much hindered. Experience has shown that local authorities are, as in fact they should be, very cautious in adopting scientific improvements. This partly arises from a proper regard for the ratepayers' money, but partly from their objection to acknowledge that they have made a mistake and to the consequent criticism of the electorate.

This being so, it would be most unfortunate if anything should be done that would hinder the progress of electrical developments in the metropolis. London is so large that it could certainly afford to get the best in the first instance; the difficulty is to ensure a continuance in the adoption of the mosi efficient methods when concerns are municipalised. To-day the generating station erected by the Council at Greenwich is practically obsolete as an up-to-date power house.

The problem is one, however, crying for solution. The need for some improvement in London electrical supply is generally admitted, as are the advantages arising from concentration. The best solution of the difficulty is probably that outlined in the report of the Council's Finance Committee issued in December, which closed with the following words:-

"The financial difficulties to which we have called the attention of the Council would to a large extent be obviated if the Council saw its way to adopt some scheme of exercising the powers sourht, if and when conferred by Parliament, by which the Council, while retaining general control, would be relieved of the responsibility of working the undertaking in whole or in part."

Whether the solution will be brought about by enlarging the existing stations, as their owners propose, or by erecting new and larger stations on more convenient sites outside, as other experts desire, is a question which must be settled by a Parliamentary Committee and the Board of Trade. But more delay in concentration will be fatal to London's industrial future, and is quite unnecessary if only the Council will realise the need for cooperating with private enterprise, as the Select Committee suggested.

NO. I 948 , VOL. 75$]$

\section{PROF. HENRI MOISSAN.}

I $T$ was with deep sorrow that the scientific world learnt of the death of the illustrious French chemist Henri Moissan, which occurred on WVednesdar, February 20, following an operation for appendicitis.

Born in Paris on September $28,{ }_{1} 85^{2}$, Moissan early developed an interest in chemistry, and in $187^{2}$ entered the laboratory of Fremy at the Muséum d'Histoire naturelle, attending also the courses of Henri Sainte-Claire Deville, Debray, and others.

This early training firmly fixed the direction of his life's work, for it is precisely along the lines so ably developed by this brilliant school of French chemists that Moissan's genius and resource in experimentation were applied. Worthily to have upheld the traditions and high quality of this school and to have widened the field of inorganic chemistry required powers of no mean order.

From 1873 to 1879 Moissan held the post of assistant in the laboratory of MM. Decaisne and Dehérain at the Muséum d'Histoire naturelle, and in 1874 published, in conjunction with $M$. Dehérain, his first contribution to science, a study of the absorption of oxygen and emission of carbonic acid by plants kept in a darkened room. In 1877 a series of papers on the oxides of the metals of the iron group was commenced, the whole work being collected and presented in 1880 as a thesis for the degree of Docteur ès sciences of the Faculty of Sciences of the Paris University. This research, carried out with much experimental skill and precision, considerably extended our knowledge of the reduction products of the oxides of iron, manganese, nickel, and chromium.

A long connection with the École supérieure de Pharmacie commenced in 1879 , by his appointment as demonstrator in chemistry; the chair of toxicolog! being given him in $188 \%$, after his memorable isolation of fluorine, and finally the professorship of chimie minérale in 1899 , when his first opportunity occurred for holding a course of lectures on chemistry.

After his graduation, Moissan, from 1879 to $188_{3}$, devoted himself chiefly to the studv of the compounds of chromium, investigating in particular the chromous salts and perchromic acid. Subsequently, in the laboratory of Debray, and with the active encouragement of Troost and Friedel, he commenced his researches upon fluorine which culminated in r 886 in the isolation of this element.

The difficulties, which had baffled the experimental ability of Humphry Davy, Faraday, Fremy, and many others, were overcome, and fluorine itself was presented to us. That this may justly be considered to be one of the wreatest achievements of experimental chemistry in the nineteenth century can be judged not so much by the brilliant result attained as by the display of indomitable pluck and perseverance which assured the successful issue.

After a number of fruitless but well-planned attempts to separate the element from its compounds with silicon, phosphorus, and arsenic, Moissan, on June 28 , I886, communicated to the Academy of Sciences the first details of his experiments on the electrolysis of anhydrous hrdrofluoric acid containing potassium bifluoride. The definite proofs of the identity and elementary nature of fluorine were presented in the following month, whilst, on November 8, Debray reported to the academy the complete conviction of the section of chemistry in the validity of the experiments.

From 1886 to $189 \mathrm{I}$ Moissan published numerous

1 See also the article on Moissan's laboratory and his work in it in NATURe, January i6, 1902, vol. lxv . p. 252. 